\title{
Communication Process In Second Language Acquisition Influenced By General Factors
}

\author{
Waode Hamsia \\ Mahasiswa Pasca Unesa \\ waode.17070996014@mhsw.unesa.ac.id
}

abstract. In communication process, there were some students who faced some problems in expressing their ideas in speaking English as the second language acquisition. The problems are especially in applying expression, choosing words, and lacking of vocabularies. The problem in applying expression was caused by an interruption and a lack of preparation. Then the next problem in choosing words was caused by the difficulties to find some approriate words and using in a grammatically correct sentences. The last in lacking of vocabularies was caused by having a few vocabularies. The purpose of this researh analyzed the communication process in second language acquisition that employed by the students. The strategies that used in communication process were influenced by some general factors. The method used a qualitative research. The data were the students' verbal and non verbal language. The instruments were observation and interview. The subjects were the students in English program who were in the fourth semester in Muhammadiyah University of Surabaya. The result showed there were eight communication strategies proposed by littlewood to solve the problems in speaking English. The communication strategies used by the students were influenced by some general factors. The factors are proficiency level, problem source, personality and learning situation. Therefore the students could maintain the conversation successfully.

Keyword: Communication, Second Language Acquisition, General Factors

\section{INTRODUCTION}

Students in Indonesia learn English as a second language that get difficulties in delivering their idea in the new language. It is because the students is still in the process of acquiring a second language. Ellis said that The term acquisition is the process where language is acquired as a result of natural and largely random exposure to language while the term learning is the process where the exposure is structured through language teaching (1990:41). In other word, that acquisition and learning were synonymous with informal and formal language learning context). In fact when the students try to communicate in a second language, they often forget the vocabulary or are confused with the grammar. The situation makes the conversation run not well, and the speaker cannot build a good communication. In communication process the students usually have some problems, especially in applying the expression, word choosing, phonology, or lack of vocabularies. To overcome these difficulties, the students must try to find a certain strategy which make them able to communicate well. The strategy can be helpful for them to achieve the goal in conversation. In this case the use of communication strategies can influence the students' success. That is why research about the communication process in second language acquisition that employed by the students need some strategies. They are used in communication process were influenced by some general factors. Therefore the choice of communication strategies is important to be done.

The communication strategies as effective ways for improving student's speaking ability have not been widely used. The students only know little about the concept of 
communication strategy. Moreover, they do not have enough knowledge about what communication strategies as well. Therefore, doing research about communication strategies is necessary in Teaching English. It is expected that the strategies can be used by the students if they are introduced to students as strategies that can assist them to express their ideas. The researcher wants to know the types of communication strategies used by the students in the fourth semester in Muhammadiyah University of Surabaya. In this case, the researcher used Littlewood's Communication Strategies as the main theory.

Communication strategies according to Littlewood (1992: 83) are ways that learners use in coping with the situation to get across the meaning, when a second language learners faces difficulties to deliver their intentions in communication. Students choose certain communication strategies when facing some different problems. Communication strategies divided into eight types used by the students in the speaking class. Those strategies are avoiding communicating, adjusting the message, using paraphrase, using approximation, creating new words, switching to the other another language. Looking at the benefit of communication strategies that employed by the students who realize the strategies that they use to keep the conversation going on. The researcher thinks that communication strategies can make the conversation continue, although the speaker does not master his second language well. This fact encourages the researcher to observe communication strategies that employed by the students to solve their speaking problem. They must have various specific communication strategies when they want to master this skill. The most effective way of mastering this skill is by practicing in real communication or conversation. When they do more to practice speaking, it can make their speaking be better. It is in line with the proverb says that practice makes perfect. In other words, it can make progress for the skill. Further, this could lead them to be a good learner. According to O'Malley (1990) that learners who are aware of their learning process and consciously could control it by applying some strategies to perceive their learning goal.

The speaking activities are encouraged to be more spontaneous in their speaking. The students have already got the knowledge about how to speak in second language in conversation from the previous semester, although they are still based on the text book. They learn to express their idea in a current topic offered by the lecturer. They spoke among their friends and communicate their ideas among them. There is significant relation in communication strategies that employed by the students who realize the strategies that they use to keep the conversation going on. The students are more successful than others who did not employ the strategies in speaking class. Therefore, the main focus of this study is communication strategies employed by students. This concept hopefully gives clear information to the English teachers about the description of general factors that affect the students to choose certain type of communication strategies and can be used to identify specific factors that influence the student to use only certain strategies. The factors are shown as follows (Ellis, 1985: 183186) that are proficiency level, the problem source, personality, and learning situation.

\section{METHODS}

The researcher used qualitative research. As Bogdan and Biklen (1982: 25) said that there are five features of qualitative research: (1) it has the natural setting as the direct source of data and the researcher is the key instrument, (2) it is descriptive, (3) it is concerned with the process rather than simply with the outcomes or products, (4) it tends to analyze data inductively, and (5) meaning is its essential concern (Researchers who use this approach are interested in the ways different people make sense out of their lives). From the explanation above, it requires a long term involvement so that the investigator presence 
becomes a natural condition. This research has observed the communication strategies used by the students. The data was taken in the form of words. The process that happened in the classroom was observed by the researcher using handy cam. The Field notes were also made during observation done in the classroom. The researcher used the theory of communication strategies by Littlewood. The identification of types of communication strategies was done through the data from transcription and notes. The second, this research also identified general factors influence the use of communication strategies. The identification of factors influence the use of communication strategies was done through observation and interview. The last, the research also identifies specific factors that influenced students to use only certain strategies by giving interview the students. It identified specific factors influence students to use only certain strategies.

The subjects of this study were in the fourth semester in Muhammadiyah University of Surabaya. 15 students are taken as the subject of this study. The data of this study were the students' utterances are from transcription, and notes. The researcher used the transcript as the main source. Another data was in the form of students' nonverbal behavior. Nonverbal here refers to hands or body movements, gestures and facial expression that were done by the students to help them overcome the problems happened during the conversation. Interview for the students was held to support this study. The interview result from the students was important to find the factors influence the students to use certain strategies.

\section{RESULTS}

\section{Communication Strategies Employed by Students}

Many students did not try to communicate with others naturally. The students in the fourth semester learnt how to apply their second language (L2) in conversation more naturally. Ellis (1997: 60) in "Second Language Acquisition" said that anyone who has tried to communicate in an L2 knows that learners frequently experience problems in saying what they want to say because of their inadequate knowledge. Furthermore the speaking activities were encouraged to be more spontaneous in their speaking. They spoke among their friends and communicate their ideas among them. In fact, they face many problems when they were asked to speak and communicate in English because English is not as means of their daily communication. To overcome these problems, the speakers tried to find a certain strategy which makes them able to communicate well. The strategy would be helpful for them to achieve the goal in conversation. In this case the use of communication strategies influenced the students' success.

In some conversations, the speakers were unable to continue their utterances because they are unable to get a particular word. In these utterances, the speakers directly asked for help from the interlocutor when they did not know the words in English. After the problem of the unknown words had been solved, they could continue their utterances again and kept the conversation flowing efficiently. No students were seeking help from dictionary or text book. This strategy was similar to non linguistic resources strategy but it has a rising tone in order to ask their friends, or to give a signal to help them solve problem. Thus, it is different with the non linguistic resources strategy that uses mime and gesture to clear the meaning but the tone does not rise or only tries to give signal to other learners to help him.

\section{General Factors Influence the Choice of the Communication Strategies. \\ Communication strategies used by the} students were influenced by many general factors, which would be different among others. The factors were from the inside or outside of individual. Every student had his or her own characteristics and chooses his or her own strategies. According to Ellis theory, 
there are four general factors that influence the use of communication strategies. Those are proficiency level, the problem source, personality and learning situation (1985:183186). The factors that influenced the use of a certain communication strategy become clearer when the strategy is associated with the data collected using an interview.

The first general factor that influenced the choice of communication strategies is proficiency level. The factor related to fluency and accuracy in speaking ability. Fluency doesn't mean speaking really fast without hesitating but using simple words to express meaning, even though longer words might be more descriptive. Furthermore fluency means speaking slowly and clearly, not speaking fast and unclearly. It depends on knowing more vocabulary and on confidence or not worrying about losing face by making mistakes. Accuracy means not making too many mistakes in grammar. In other words, the students speak more accurately.

Some students were asked to convey the information in the form of interview. In the interview the researcher asked the students who used some different strategies that were influenced by the difference of the proficiency level. In this speaking class, not all of students could be expected to express themselves fluently without making mistakes at the same time. In other words, the students might be unable to find the right words to express their ideas due to their low vocabulary mastery. In this case in making some mistakes is a natural part of learning a language, and students would choose certain communication strategies when expressing their ideas in oral English so that the others understand and react to their speaking. For instance, the speakers could use the gestures in expressing their intended meaning and also asked for help from their friends what the words are in English. Thus, it could be concluded that the use of these strategies are mostly influenced by the low proficiency level of the target language. From the result of the interview the proficiency level, it could be found that influenced the use of some strategies. Therefore, the different proficiency level may affect the use of different communication strategies.

The second general factor that influences the choice of communication strategies was the problem source. The problem source is related to the nature of the task. In this speaking class, students were introduced to some topics that might interest them, but of course not everybody is equally interested in the same topics. A topic like "Why English is very important" tends to interest most students in fourth semester but topics like English may not interest some students. Their difficulties in giving opinions relate to their personal experiences and background knowledge of a topic. The differences of the tasks influence a language learner's selection of a specific communication strategy. In the speaking class that became the subject of this study various tasks were given by the lecturer. Hopefully, these tasks would motivate students to speak and use communication strategies when meeting the difficulty in expressing their ideas in oral English. Not only the task can motivate but also stimulate to speak with their friends.

The third general factor that influences the choice of communication strategies was personality. The term personality refers to whether students are active or not. The students would be identified from their performance during activities in the speaking class. Active students were those who could find their own way (without always having to be guided by the lecturer through conversation activities), be creative, make intelligent guesses, make their own opportunities for practice, and use contextual clues. The active students would be seen from their process of taking part during conversation activities. Some active students were ready for the discussion. They could share their experiences, ideas, and opinions. Sharing in a two-way process is a process of explaining 
and listening to others, and reacting to them. Therefore, the active students who felt more comfortable when taking their time could be successful.

The fourth factor that influences the choice of communication strategies was learning situation. The learning situation in this research is related to classroom speaking activities that students were interacting with one or more participants. During the observation, all students must speak up in any conversation. This was called "turn-taking", a term which referred to the way in which participants in the conversation got their chance to speak. The students did this by knowing some signals verbally or visually from the other students to give them a turn. In another way the students could recognize when one of the students was signaling that she or he wanted to finish. Therefore when students were working together in speaking activities, they could talk more to share their ideas in enjoyable learning situation. From the result of the interview, it can be found that the learning situation that is related to classroom situation influenced the use of paraphrase strategy. Therefore, the learning situation might make the students used fewer strategies in a classroom environment, particularly if the pedagogic focused on the correct L2 use, rather than on fluent communication.

\section{Specific Factors Faced by the Students}

In communication process, the students faced some specific factors when they only use certain strategies. The factors are especially in applying the expression, choosing word, and lacking of vocabularies. The factors become clearer when they are associated with the data collected using an interview. The first specific factor is in applying the expression in oral English. The students used some certain communication strategies when they faced the factor. The kinds of the communication strategies employed by the students were avoiding communication and adjusting the message. Based on the result of interview, the students said that they applied these strategies when got difficulties in applying the expression in a good way based on the topic given. One of the difficulties was an interruption from another student who came into the classroom late, the speaker was speaking. Moreover the interruption would stop speaking for a short period which made the speaker unable to give his/her opinion continuously. The situation gave a little interaction from the other students.

The second specific factor is in choosing words. Some students used a certain communication strategy when they faced this factor. One of the communication strategies employed by the students was using approximation. Based on the result of the interview, the students said that they applied this strategy when they got difficulties in choosing an appropriate word to describe the intended meaning they refer to, so they used other words that were less specific. Moreover, another difficulty was how the word should be used in a grammatically correct sentence. Therefore, the students used approximation strategy when they faced the factor in choosing an appropriate word.

The third specific factor is in lacking of vocabularies in English. It means the students' vocabularies were not as many as necessary to express their ideas due to their low vocabulary mastery. The students used some certain communication strategies when faced with this factor. The kinds of the communication strategies employed by the students were using non-linguistic resources and seeking help. Based on the result of the interview, the students said that they applied these strategies when they with very few vocabularies were required to survive in speaking activities so they gave the sign, because they needed a help and wanted to emphasize their intended meaning. Either using nonlinguistic resources or seeking help were good communication strategies. Therefore the students may simultaneously use both of the strategies, such as gestures in order to indicate the idea that 
they wished to express. Especially in seeking help, the voice has a rising tone in order to ask their friend's help and the students tried to give a signal to their friends to help them solve problems with what to say.

\section{CONCLUSION}

The communication process in second language acquisition that employed by the students need some strategies that were influenced by some general factors. Therefore the choice of communication strategies is important to be done. The students use eight strategies as proposed by Littlewood. They are 1) avoiding communication, 2) adjusting the message, 3) using paraphrase, 4) using approximation, 5) creating new words, 6) switching to the native language, 7) using nonlinguistic resources and 8) seeking help. The communication strategies used by the students were influenced by some general factors. The factors are proficiency level, problem source, personality and learning situation. The first factor, proficiency level is related to fluency and accuracy. The factor influenced the use of paraphrase especially for advanced students who were more sensitive in the selection of specific strategy. The second factor, problem source is that related to the nature of the task. The factor influenced the use of avoiding communication and adjusting the messages. Furthermore, the third factor, personality is that focused on non active and active students. The factor influenced the use of switching to the native language and seeking help strategy especially for non active students. They used those strategies to maintain their conversation. The last factor is learning situation that is in the classroom. The factor influenced the use of paraphrase due to the pedagogic focused on the correct L2 use rather than on fluent communication. In communication process the students faced some specific factors too when they only used certain strategies. The factors were in applying the expression, choosing word, and lacking of vocabularies. First of all, the factor in applying the expression was caused by an interruption and a minimal preparation. Then the factor in choosing words was caused by getting difficulties to find some appropriate words and using in a grammatically correct sentence. Next, the factor in lacking of vocabulary was caused by having a few vocabularies. The students used some certain strategies to solve the problems in speaking activities.

\section{REEFERENCES}

Bialystok, Ellen. 1990. Communication Strategies: A Psychological Analysis of Second Language Use. London: Basil Blackwell Ltd.

Bogdan, R.C. \& Biklen, S.K. 1982. Qualitative Research for Education: An Introduction to Theory and Methods. Boston: Allyn and Bacon.

Ellis, Rod. 1985. Understanding Second Language Acquisition. Oxford: Oxford University Press

Ellis, Rod. 1990. Instructed Second Language Acquisition. Cambridge: Basil Blackwell, Inc

Ellis, Rod. 1997. Second Language acquisition. Oxford: Oxford University Press.

Littlewood, W. 1992. Foreign and Second Language Learning. New York: Cambridge University Press

O’Malley, J. M., \& Chamot, A.U. (1990). Learning strategies in second language acquisition. Cambridge: Cambridge University Press. 